\title{
Acute Abdomen in the 17th Week of Twin Pregnancy due to Ovarian Torsion - A Late Complication of IVF
}

\author{
Akutes Abdomen wegen Torsion des Ovars in der 17. Schwangerschaftswoche \\ als Spätkomplikation der IVF-Behandlung
}

Authors

Affiliations
D. Habek ${ }^{1}$, R. Bauman ${ }^{2}$, L. Rukavina Kralj ${ }^{3}$, T. Hafner ${ }^{2}$, T. Turudic ${ }^{2}$, S. Vujisic ${ }^{4}$

${ }^{1}$ University Ob/Gyn Department, Croatian Catholic University Zagreb, Clinical Hospital Sveti Duh Zagreb, Zagreb, Croatia

2 Clinical Hospital Sveti Duh Zagreb, Zagreb, Croatia

${ }^{3}$ Dom zdravlja Zagreb zapad, Zagreb, Croatia

4 “Beta Plus" Policlinic for Obstetrics and Gynecology Zagreb, Zagreb, Croatia

Key words
IVF
ovary
torsion
pregnancy
Schlüsselwörter
IVF
Eileiter
Torsion
- Schwangerschaft

received 14.1.2013

revised $\quad 1.8 .2016$

accepted 1.9.2016

\section{Bibliography}

DOI http://dx.doi.org/ 10.1055/s-0042-116492

Geburtsh Frauenheilk 2016; 76: 1345-1349 @ Georg Thieme

Verlag KG Stuttgart · New York . ISSN 0016-5751

\section{Correspondence}

Lea Rukavina Kralj

Dom zdravlja Zagreb zapad

Nova cesta 85 a

10000 Zagreb

Croatia

learukavinakralj@gmail.com

\section{Abstract}

$\nabla$

Background: A 32-year-old woman with tubal factor infertility due to bilateral laparoscopic salpingectomy conceived twins with in vitro fertilization (IVF). She developed moderate ovarian hyperstimulation syndrome which was treated with anticoagulant therapy. The subsequent course of the twin pregnancy was normal until the 17th week of gestation when she presented to hospital because of a sharp pain in the right lower abdomen which ceased after admission.

Case: Except for a single incident of vomiting, patient had no other subjective symptoms. The clinical examination showed tenderness of the lower right abdominal segment on palpation. The surgeon and the urologist found no signs of an acute surgical or urologic condition, and laboratory findings were within normal reference ranges for pregnant women. Two days after admission the pain reappeared; it was now much stronger and colic-like. The pain was initially located supraumbilically but subsequently spread diffusely across the lower abdomen. Abdominal guarding was present and laboratory findings showed an increase in inflammatory parameters. An enlarged and edematous right ovary was found on transvaginal ultrasound.

Conclusion: Exploratory laparotomy via a vertical midline abdominal transection revealed a torqued necrotic right ovary with elements of inflammation and inflammatory adhesions involving the entire pelvis. The patient underwent right-sided ovariectomy and adhesiolysis. Recovered was normal and the patient was delivered of healthy twins in the 37th week of gestation.

\section{Zusammenfassung \\ V}

Hintergrund: Eine 32-jährige Frau mit Infertilität infolge einer früheren bilateralen Salpingektomie wurde durch In-vitro-Fertilisation (IVF) schwanger. Kurz darauf entwickelte sie ein ovarielles Hyperstimulationssyndrom mittleren Schweregrads, das mit Antikoagulanzien behandelt wurde. Die Zwillingsschwangerschaft entwickelte sich normal bis zur 17. Schwangerschaftswoche, als die Patientin wegen akuter rechtsseitiger Schmerzen im Unterbauch im Krankenhaus vorstellig wurde. Nach der Aufnahme im Krankenhaus verschwanden die Schmerzen wieder, und außer einem Fall von Erbrechen hatte die Patientin keine Symptome.

Fallbericht: Bei der klinischen Untersuchung zeigte sich eine Druckdolenz im rechten Unterbauch. Der Chirurg und der Urologe fanden keine Anzeichen für eine akute chirurgische oder urologische Krankheit, und die Laborwerte waren im normalen Bereich. Zwei Tage nach der Aufnahme im Krankenhaus kamen die Schmerzen wieder. Diesmal waren sie intensiver und kolikähnlich. Die Schmerzen waren zunächst supraumbilikal, um sich danach im ganzen Unterbauch zu verbreiten. Sie gingen mit abdomineller Abwehrspannung einher, und die Laborwerte stiegen an. Transvaginaler Ultraschall zeigte einen ödematös veränderten und vergrößerten Eierstock auf der rechten Seite.

Schlussfolgerung: Bei der explorativen Laparotomie fand man einen nekrotischen rechten Eierstock mit mehrfacher Torsion, Anzeichen von Entzündung und Adhäsionen im ganzen Beckenraum. Die Patientin wurde einer rechtsseitigen Ovarektomie und einer linksseitigen Adhäsiolyse unterzogen. Ihre Genesung verlief ohne Zwischenfälle, und sie brachte in der 37. Schwangerschaftswoche gesunde Zwillinge per Kaiserschnittentbindung zur Welt. 


\section{Introduction}

Torsion of a hyperstimulated ovary after in vitro fertilization (IVF) has been known to occur but is quite rare. The incidence of ovarian torsion after IVF treatment has been reported to range from 0.08 to $0.13 \%[1,2]$. It has also been noted in patients with ovarian hyperstimulation syndrome (OHSS) following gonadotropin therapy $[3,4]$ and IVF [5-10]. This is understandable since large multicystic ovaries are more predisposed to sudden adnexal torsion. Kemmann et al. [3] have suggested that in the presence of pregnancy (especially multiple pregnancy), the enlarged uterus may stretch the utero-ovarian ligaments, pushing the ovaries out of the pelvis. This may then reinforce the enlarged ovaries' propensity to torsion.

Ovarian torsion associated with OHSS usually appears between 6 and 13 weeks of gestation [5]. Therapy consists of laparoscopy or laparotomy, and gestational age at the onset of ovarian torsion is an important parameter determining the diagnostic/therapeutic approach. Some publications have stated that laparoscopy can be performed in any trimester $[11,12]$. However, as with other types of surgery performed during pregnancy, the optimal time for surgery is early in the second trimester [13-15]. Laparotomy is often preferred to laparoscopy when a large solid ovarian mass is present on preoperative ultrasonography or when the patient has had multiple prior surgeries and/or a history of adhesive disease [11], which was the case in our patient. Initial symptoms of ovarian torsion include tenderness of the lower abdomen as well as severe pain in the lower abdomen. Other symptoms associated with ovarian torsion are nausea, diarrhea, vomiting, constipation, mild fever and tachycardia. Patients may experience one or all of these symptoms, but the most pronounced symptom is extreme lower abdominal pain. It is important to bear other possible causes of acute abdomen in mind in both early and late pregnancy. In gynecology and obstetrics, acute abdomen syndrome can have an inflammatory, ischemic-obstructive or hemorrhagic intra-abdominal etiology, resulting from a complication of primary disease, pathological processes in specific organs or injury (to the genital, gastrointestinal, urinary, vascular, neurological or musculoskeletal system). Clinical and ultrasound examination, laparoscopy (in the early stage of pregnancy) and laboratory findings are the standard diagnostic methods used to evaluate the etiology of acute abdomen syndrome in obstetrics.

Rare cases of acute abdomen syndrome due to gynecological or obstetric causes with an atypical clinical picture have been described in the literature. This case report describes a patient with ovarian torsion presenting in late pregnancy as a non-typical complication of IVF. The patient underwent exploratory laparotomy followed by adhesiolysis and ovariectomy. The diagnosis made at laparotomy was confirmed during subsequent treatment.

\section{Case Report}

$\checkmark$

A 32-year-old nulliparous woman joined the IVF program of our clinic to become pregnant. Her previous medical history included multiple laparoscopic procedures. Thus, she had previously undergone laparoscopic surgery of a right inguinal hernia, had had left laparoscopic salpingectomy for extrauterine pregnancy and right laparoscopic salpingectomy, again for extrauterine pregnancy.

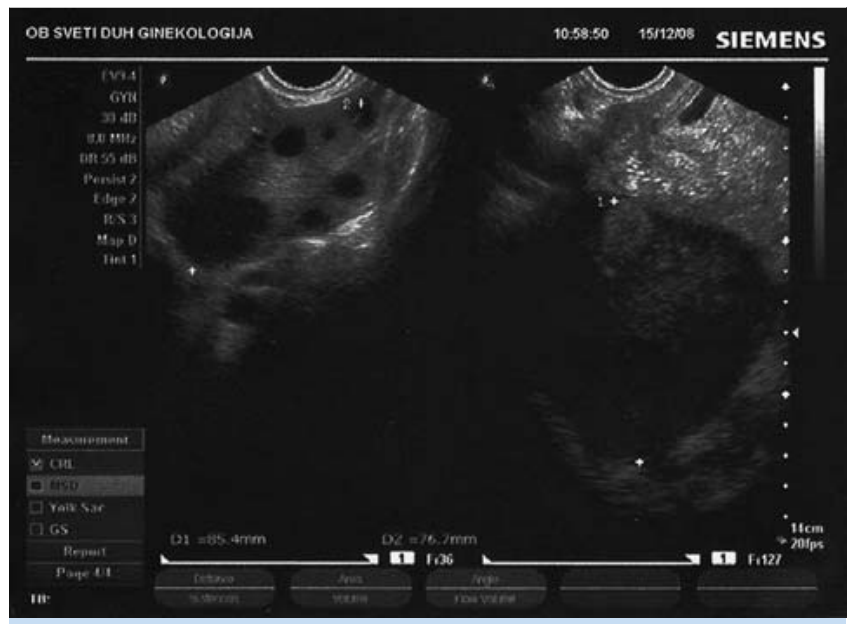

Fig. 1 Ultrasound of the ovaries in the 7th week of gestation.

Induction of ovulation was achieved with daily injections of $225 \mathrm{IU}$ of HP-hMG administered from the 2nd to the 4th day of the menstrual cycle, followed by $150 \mathrm{IU} /$ day of HP-hMG (Menopur, Ferring, Kiel, Germany) administered from the 5th to the 11th day of the menstrual cycle when the ultrasound criteria for triggering ovulation were fulfilled (at least 2 follicles with a diameter of $18 \mathrm{~mm}$ ). LH antagonist (Cetrotide, Baxter Oncology $\mathrm{GmbH}$, Frankfurt, Germany) was given from the 8th to the 11th day of the menstrual cycle to prevent a premature LH surge. The timing of follicle aspiration was achieved by the administration of 10000 IU rhCG (Ovitrelle, Serono, Bari, Italy) 36 hours prior to the procedure. Eight oocytes were collected during aspiration, of which 4 oocytes were subsequently fertilized, but only 2 embryos were of good quality (8-cell embryo - grade 1 ). These 2 embryos were transferred into the uterus on the 3rd day after aspiration. The right ovary had a diameter of $7 \times 5 \mathrm{~cm}$, the left ovary had a diameter of $6 \times 5 \mathrm{~cm}$, and no retrouterine fluid was visualized on ultrasound on the day of embryo transfer. After embryo transfer, the patient was given micronized progesterone for vaginal application, $3 \times 200 \mathrm{mg} /$ day. Four weeks later, ultrasound revealed a viable twin pregnancy in utero.

Five weeks after embryo transfer, the patient was admitted to our department for moderate lower abdominal pain believed at the time to be due to enlarged ovaries. Ultrasound showed a small amount of free fluid in the abdomen $(5 \times 4 \mathrm{~cm})$, with a right ovarian diameter of $8.5 \times 6.3 \mathrm{~cm}$ and a left ovarian diameter of $7.6 \times 5.3 \mathrm{~cm}$ ( Fig. 1). Laboratory findings showed mild hemoconcentration ( $\mathrm{Hb} 139 \mathrm{~g} / \mathrm{L}$ (reference values for non-pregnant women: $110-160 \mathrm{~g} / \mathrm{L}$ ) and an Hct level of $0.45 \mathrm{~L} / \mathrm{L}$ (reference values for non-pregnant women: $0.35-0.48 \mathrm{~L} / \mathrm{L}$ ). There were no signs of massive tension ascites, severe dyspnea, vomiting, diarrhea or hydrothorax. Based on the presenting symptoms and the laboratory findings, our patient was classified as having moderate ovarian hyperstimulation syndrome (OHSS) [16]. According to the OHSS classification introduced by Rizk and Aboulghar in 1999, moderate OHSS includes discomfort, pain, nausea, distension, ultrasonic evidence of ascites and enlarged ovaries, with normal hematological and biological profiles. In hospital the patient was given Fraxiparin therapy and the symptoms gradually receded. She was discharged from hospital with the recommendation to take acetylsalicylic acid $100 \mathrm{mg} /$ day and micronized progesterone $400 \mathrm{mg} /$ day applied vaginally. It is possible that 
the pain she experienced in the 7th week of gestation was due to torsion or semi-torsion of the adnexa and not the result of enlarged ovaries. In the 17th week of her twin pregnancy after IVF, patient was again referred to our gynecologic department for sharp pain in the right lower abdomen, followed by a single incident of vomiting. Prior to being referred to the gynecological department, the patient was examined by a surgeon and an urologist. The surgeon found no signs indicating an acute surgical condition, and the urologist performed a microbiological urine analysis which was found to be sterile. The patient's laboratory findings at the time of admission were: L 10.27 (3.3-9.3) $\times 10^{9} / \mathrm{L}$, nonsegm. 6\% (0-4\%), E 3.79 (3.8-4.9) × 10 $12 / \mathrm{L}, \mathrm{Hb} 101(120-160) \mathrm{g} / \mathrm{L}$, CRP 2.7 (0-10) mg/L; urine sediment: E 48 (0-10), L 101 (0-10). The patient was not nauseous, did not have diarrhea or experience repetitive vomiting. The pain disappeared soon after the patient was admitted. The difference between axillary and rectal temperature was less than one degree Celsius. Clinical examination revealed tenderness in the right lower abdominal quadrant. Gynecological examination showed normal serous vaginal secretion and a cervix of normal size and appearance, closed on palpation. The patient experienced pain during bimanual examination of the right adnexa. Gynecological ultrasound showed a firm, closed, T-shaped cervix with a length of $48 \mathrm{~mm}$. Abdominal ultrasound showed no pathological findings; the fetuses were vital with normal biometric measures and regular fetal dynamics; the amount of amniotic fluid was normal and the shape of the placenta was regular and normal. Lumbar succussion was bilaterally negative, and ultrasound of the kidneys showed no pathology.

The pain reappeared on the second day after admission (in the 17th week of gestation). The pain was more intense and coliclike. The pain was initially located supraumbilically but subsequently spread diffusely across the lower abdomen, and the patient became febrile (temperature of around $38^{\circ} \mathrm{C}$ ). After repeat laboratory blood analysis showed an increase in inflammatory parameters (CRP $91.6 \mathrm{mg} / \mathrm{L}, \mathrm{L} 14,16 \times 10^{9} / \mathrm{L}$, immature leukocytes $11 \%)$, therapy consisting of an antipyretic and the parenterally administered antibiotic cefuroxime was initiated. The patient was again examined by a surgeon and an interdisciplinary team to exclude the presence of acute surgical condition requiring surgery. The repeat urological exam was again normal. Since the abdominal pain persisted, transvaginal ultrasound was performed which showed an enlarged and edematous right ovary. The inflammatory parameters continued to rise (CRP $138 \mathrm{mg} / \mathrm{L}$, L $15 \times 10^{9} / \mathrm{L}$ ) and guarding, a sign of acute abdomen, developed. The decision was taken to perform exploratory laparotomy.

Laparotomy was performed on the 3rd day of admission ( $\bullet$ Fig. 2) with access obtained through a Pfannenstiel transverse incision. Intraoperative findings included purulent and hemorrhagic secretions in the abdominal cavity, which were aspirated and sent for microbiological analysis. Inflammatory adhesions involving the entire pelvis were resolved by adhesiolysis. The right ovary was enlarged and necrotic. It was the size of a man's fist, five times torqued and filled the pouch of Douglas. The ovary was removed by right-sided ovariectomy and sent for immediate pathohistological analysis ( Fig. 3). The removed tissue consisting of an edematous torqued ovary with elements of inflammation was confirmed to be hemorrhagic. The left ovary was also covered in adhesions and following ovariolysis it was also shown to be enlarged (the size of a tangerine), consisting of many follicles and corpora lutea. Appendectomy was also done for concomitant catarrhal appendicitis.

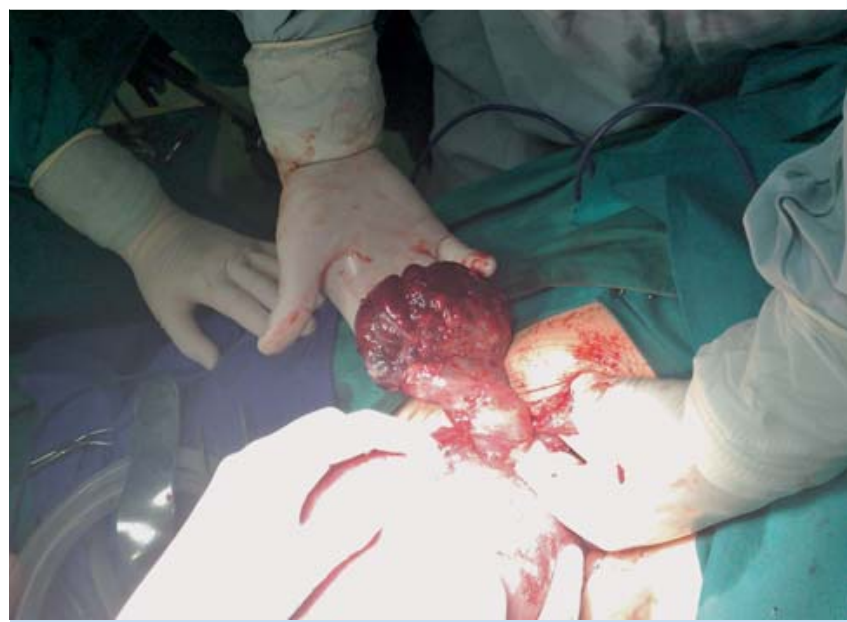

Fig. 2 Cause of acute abdomen in second trimester of twin pregnancy after IVF was five times torquated right ovary, which was revealed by explorative laparotomy.

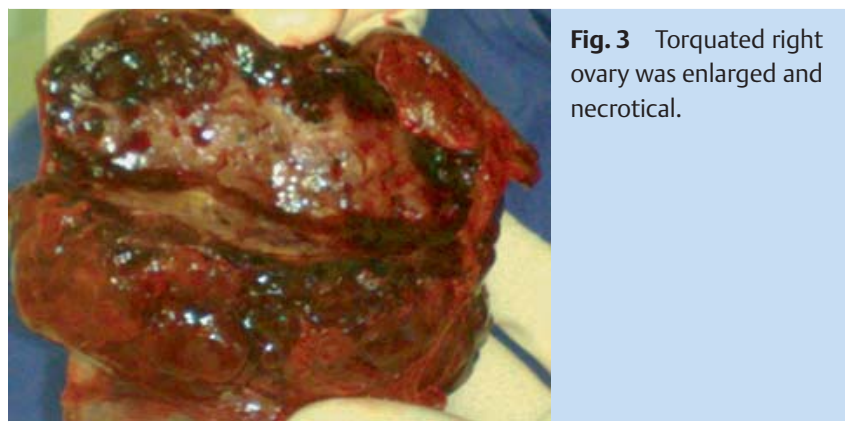

The postoperative course was uneventful. The patient remained in hospital for a further 11 days after surgery, spending a total of 16 days in hospital. Parenteral antibiotic therapy (cefuroxime $3 \times 1.5 \mathrm{~g} / 24 \mathrm{~h}$ ) was started 1 day prior to surgery. After 9 days of parenteral administration, the therapy was changed to oral intake (cefuroxime $2 \times 500 \mathrm{mg} / 24 \mathrm{~h}$ ) for a further 7 days. Control laboratory findings were within reference values for pregnant women. The patient was discharged in a good overall condition. The physiological findings of the gynecological exam corresponded to the gestational age, and obstetric findings on ultrasound were normal (T-shaped, $37 \mathrm{~mm}$ long cervix, both fetuses vital with stable hemodynamics, normal biometric measures and visible morphology).

The pregnancy continued without further complications until the 37th week when the patient had cesarean section for twin breech presentation and two healthy babies were delivered. Cesarean section was performed without any complications. A few soft adhesions to the left ovary were found intraoperatively and resolved by adhesiolysis. The appearance of the other intraabdominal organs was normal.

\section{Discussion}

\section{$\nabla$}

Adnexal torsion is a rare cause of acute abdominal pain during pregnancy. It is frequently associated with ovarian stimulation for in vitro fertilization (IVF) or ovarian masses, mainly of func- 
tional origin. It is uncommon for a normal-sized ovary to become torqued, but enlarged multicystic ovaries and a prior history of OHSS may predispose to adnexal torsion.

The symptoms are nonspecific; the classic presentation is sharp localized right or left lower abdominal pain and tenderness with a palpable mass and peritoneal signs $[5,17]$. Additional symptoms can be nausea, vomiting, low-grade fever and leukocytosis $[4,18]$. Adnexal torsion is rarely bilateral and is more common on the right side, perhaps because the sigmoid colon leaves little space for left adnexal mobility. Ovarian torsion should be suspected and ruled out in any female undergoing ovulation induction for IUI or IVF who presents with severe abdominal pain, because a delay in diagnosis and management could lead to ischemic necrosis of the ovary.

Adnexal torsion in patients with OHSS usually appears in the first trimester of pregnancy. Mashiach et al. [5] analyzed the clinical features of 12 pregnant patients with OHSS and ovarian torsion. They found that symptoms characteristically appeared acutely between 6 and 13 weeks of gestation. The interval between the onset of symptoms and admission to hospital ranged from 20 to 150 hours (mean 43 hours). The delay between hospital admission and surgery was 3-72 hours (mean 15.5 hours).

Unlike these cases, our patient presented with lower abdominal pain in the 17th week of gestation. The time between the onset of symptoms and admission to hospital was six hours and surgery was performed 90 hours after admission as at one point the symptoms appeared to have resolved. Atypical late onset of adnexal torsion has also described by Rackow et al. [19] in a patient where unilateral adnexal torsion at 7 weeks of gestation was followed by subsequent contralateral adnexal torsion that occurred at 19 weeks of gestation.

The differential diagnosis of severe abdominal pain or acute abdomen in pregnant women is similar to that for non-pregnant women, with a few conditions specific to pregnancy. The incidence of acute abdomen in pregnancy is 1 in 500-635 pregnancies [20]. It is important to differentiate between pregnancy-related, gynecological and other abdominal causes of acute abdomen in pregnancy, which can have an inflammatory, obstructive-ischemic or hemorrhagic etiology [21].

Although various treatments for this condition have been reported in the literature, the key to a successful outcome is still early diagnosis and prompt surgical intervention. Simple untwisting of the ovary at the time of laparoscopy may be all that is required if the condition is picked up early $[4,5,18]$. Late diagnosis will often result in a devitalized ovary that is beyond salvage. In this situation, adnexectomy or ovariectomy may be the only option $[2,4]$. The choice of surgical approach for diagnosis and treatment depends on several factors such as gestational age, clinical appearance and the skill of the gynecologist performing the surgery. Although laparoscopy appears to be well tolerated in pregnancy, large multicenter prospective studies are required to underpin recommendations on the use of laparoscopy in pregnancy $[22,23]$.

The advantages of laparoscopic surgery are similar for pregnant and non-pregnant women: less postoperative pain, less postoperative ileus, reduced adhesion formation, shorter hospital stays, and a faster return to normal activities [24]. The potential concerns about performing it during pregnancy include the rise in intraabdominal pressure during pneumoperitoneum which could decrease utero-placental blood flow and result in fetal hypoxia, potential fetal acidosis from the absorption of carbon dioxide, and direct or indirect fetal injury in the event of uterine per- foration by the trocar or Veress needle. The best outcome data available on this issue was obtained retrospectively from a study of Swedish health registries [25]. This study compared the outcome of 2181 laparoscopies performed in pregnant patients prior to 20 weeks of gestation with the outcome of 1522 laparotomies performed in a similar population. There were no significant differences between groups for any of the measured outcomes 'birth weight', 'gestational duration', 'intrauterine growth restriction', 'congenital malformations', 'stillbirths', or 'neonatal deaths'.

Although in their recently published guidelines on the diagnosis, treatment, and use of laparoscopy for surgical problems during pregnancy Pearl and al. stated that indications for laparoscopy to treat acute abdominal processes are the same for pregnant and non-pregnant patients and that laparoscopy can be performed in any trimester, they emphasize that laparotomy is often preferable in the presence of a large solid ovarian mass on preoperative ultrasonography and when the patient has had multiple prior surgeries and/or a history of adhesive disease [11].

In our case, laparotomy was shown to be appropriate choice for the patient who had had three prior laparoscopic procedures causing numerous adhesions and fixation of ovary to the back of the uterus. Another reason for the choice of laparotomy was the size of the gravid uterus, which was above the level of the navel. The twin pregnancy continued until the 37th week of gestation when the patient was delivered of twins by cesarean section via the same transverse incision used for the laparotomy.

\section{Conclusion for Practice}

Acute abdomen in pregnancy remains one of the most challenging diagnostic and therapeutic problems, and adnexal torsion is a rare but recognized complication that can occur in pregnant patients with hyperstimulated ovaries following IVF/ET. With the increasing use of IVF and other assisted reproductive techniques, physicians involved in the care of these women must be aware of the possibility of adnexal torsion, even in late pregnancy. Although the role of laparoscopy in resolving cases of acute abdomen in pregnancy is increasing, laparotomy is a good method to diagnose and treat patients who have previously undergone multiple laparoscopic procedures and present with ovarian torsion in late pregnancy.

\section{Conflict of Interest}

$\nabla$

None.

\section{References}

1 Govaerts I, Devreker F, Delbaere A et al. Short-term medical complications of 1500 oocyte retrievals for in vitro fertilization and embryo transfer. Eur J Obstet Gynecol Reprod Biol 1998; 77: 239-243

2 Roest J, Mous HV, Zeilmaker GH et al. The incidence of major clinical complications in a Dutch transport IVF programme. Hum Reprod Update 1996; 2 : 345-353

3 Kemmann E, Ghazi DM, Corsan GH. Adnexal torsion in menotropin-induced pregnancies. Obstet Gynecol 1990; 76 (3 Pt 1): 403-406

4 Mashiach S, Bider D, Moran O et al. Adnexal torsion of hyperstimulated ovaries in pregnancies after gonadotropin therapy. Fertil Steril 1990; 53: $76-80$

5 Ben-Rafael Z, Bider D, Mashiach S. Laparoscopic unwinding of twisted ischemic hemorrhagic adnexum after in vitro fertilization. Fertil Steril 1990; 53: 569-571 
6 Practice Committe of the American Society for Reproductive Medicine. Ovarian hyperstimulation syndrome. Fertil Steril 2008; 90 (5 Suppl.): S188-S193

7 Papanikolaou EG, Humaidan P, Polyzos N et al. New algorithm for OHSS prevention. Reprod Biol Endocrinol 2011; 9: 147

8 Golan A, Ron-El R, Herman A et al. Ovarian hyperstimulation syndrome: an update review. Obstet Gynecol Surv 1989; 44: 430-440

9 Bung P, Plath H, Prietl G et al. Ileus in der Spätschwangerschaft - Folge der Follikelpunktion im Rahmen der In-vitro-Fertilisation? Geburtsh Frauenheilk 1996; 56: 252-253

10 Gorkemli H, Camus M, Clasen K. Adnexal torsion after gonadotrophin ovulation induction for IVF or ICSI and its conservative treatment. Arch Gynecol Obstet 2002; 267: 4-6

11 Pearl J, Price R, Richardson Wet al.; Society of American Gastrointestinal Endoscopic Surgeons. Guidelines for diagnosis, treatment, and use of laparoscopy for surgical problems during pregnancy. Surg Endosc 2011; 25: 3479-3492

12 Lenglet $Y$, Roman H, Rabishong B et al. [Laparoscopic management of ovarian cysts during pregnancy]. Gynecol Obstet Fertil 2006; 34: 101106

13 Wilcox AJ, Weinberg CR, O'Connor JF et al. Incidence of early loss of pregnancy. N Engl J Med 1988; 319: 189-194

14 Boklage CE. Survival probability of human conceptions from fertilization to term. Int J Fertil 1990; 35: 75, 79-80, 81-94

15 Cohen-Kerem $R$, Railton C, Oren $D$ et al. Pregnancy outcome following non-obstetric surgical intervention. Am J Surg 2005; 190: 467-473
16 Aboulghar MA, Mansour RT. Ovarian hyperstimulation syndrome: classifications and critical analysis of preventive measures. Hum Reprod Update 2003; 9: 275-289

17 Tazuke S, Nezhat CR, Phillips DR et al. Removal of adnexal masses by operative laparoscopy during pregnancy. J Am Assoc Gynecol Laparosc 1996; 3 (Suppl.): S50

18 Bider D, Ben-Rafael Z, Goldenberg $M$ et al. Pregnancy outcome after unwinding of twisted ischaemic-haemorrhagic adnexa. Br J Obstet Gynecol 1989; 96: 428-430

19 Rackow BW, Patrizio P. Successful pregnancy complicated by early and late adnexal torsion after in vitro fertilization. Fertil Steril 2007; 87: 697.e9-697.e12

20 Augustin G, Majerovic M. Non obstetrical acute abdomen during pregnancy. Eur J Obstet Gynaecol Reprod Biol 2007; 131: 4-12

21 Habek D, Premuzić M, Cerkez Habek J. [Syndrome of acute abdomen in gynaecology and obstetrics]. Acta Med Croatica 2006; 60: 227-235

22 Kilpatrick CC, Orejuela FJ. Management of the acute abdomen in pregnancy: a review. Curr Opin Obstet Gynecol 2008; 20: 534-539

23 Weber Sánchez A, Garteiz Martínez D, Itzkovich RN et al. [Analysis of the increasing role of laparoscopy in the management of acute abdomen in pregnancy]. Ginecol Obstet Mex 2001; 69: 422-430

24 Andreoli M, Servakov M, Meyers $P$ et al. Laparoscopic surgery during pregnancy. J Am Assoc Gynecol Laparosc 1999; 6: 229-233

25 Reedy MB, Källén B, Kuehl TJ. Laparoscopy during pregnancy: a study of five fetal outcome parameters with use of the Swedish Health Registry. Am J Obstet Gynecol 1997; 177: 673-679 